\title{
Erratum to: On the Dissolution Behavior of Sulfur in Ternary Silicate Slags
}

\author{
YOUN-BAE KANG and JOO HYUN PARK
}

DOI: $10.1007 / \mathrm{s} 11663-011-9595-1$

(C) The Minerals, Metals \& Materials Society and ASM International 2011

\section{Erratum to: Metallurgical and Materials Transactions B} DOI: 10.1007/s11663-011-9541-2

THERE is a typo in Table II. The last parameter (temperature dependent) in the Gibbs energy expression of Reaction [11] was wrong. The correct value is $\mathbf{- 1 3 3 . 8 8 8 T}$ not $-133888 T$, as shown below:

Also, information for the Reference 1 is to be revised as:

Table II. Gibbs Free Energy for the Reaction [11] from Eriksson et al. ${ }^{[18]}(\mathrm{J} / \mathrm{mol})$ *

$\Delta G_{[11]}=-158218+19.456 T-37932\left(\frac{2 n_{\mathrm{SiO}_{2}}}{n_{\mathrm{CaO}}+2 n_{\mathrm{SiO}_{2}}}\right)-90148\left(\frac{2 n_{\mathrm{SiO}_{2}}}{n_{\mathrm{CaO}}+2 n_{\mathrm{SiO}_{2}}}\right)^{5}+(439893-133.888 T)\left(\frac{2 n_{\mathrm{SiO}_{2}}}{n_{\mathrm{CaO}}+2 n_{\mathrm{SiO}_{2}}}\right)^{7}$

$* n_{i}$ stands for the number of moles of $i$.

YOUN-BAE KANG, Assistant Professor, is with the Graduate Institute of Ferrous Technology, Pohang University of Science and Technology, Pohang, Republic of Korea. Contact e-mail: ybkang@ postech.ac.kr JOO HYUN PARK, Assistant Professor, is with the School of Materials Science and Engineering, University of Ulsan, Ulsan, Republic of Korea.

The online version of the original article can be found under doi:10.1007/s11663-011-9541-2.

Article published online October 25, 2011. 